\title{
STATISTICAL MODELS OF RENEWABLE ENERGY INTERMITTENCY
}

\author{
I U Rakhmonov ${ }^{l *}, K M$ Reymov $^{2}$ \\ ${ }^{1}$ Tashkent State Technical University named after Islam Karimov, 100095, Uzbekistan, Tashkent, University St. 2A \\ ${ }^{2}$ Karakalpak State University, 230100, Uzbekistan, Nukus, Ch. Abdirov St.1
}

\begin{abstract}
One of the big mitigating factors of intermittency is the smoothing effect of geographical distribution of variable renewable energy (VRE ) plants on the aggregate power output of VRE generation on a utility network. The greater the distance between two renewable plants, the less likely their output is to be affected by the same weather event (e.g. cloud coverage, storms, dust storms). This is similarly the case for smaller timescales. Further, different technologies can often be uncorrelated or even negatively correlated (e.g. wind and solar) which reduces the integration cost. In this article analyzed and quantify the expected intermittency in Uzbekistan focusing on the geographical dispersion by looking at various sites as well as by looking at a portfolio composed of different technologies.
\end{abstract}

\section{Introduction}

A big concern for the stakeholders in Uzbekistan is the intermittent nature of variable renewable energy (VRE) and the need to be able to regulate the power output of thermal generators to balance these fluctuations and the associated cost of doing so. Therefore, there is a need to quantify the intermittency and plan the penetration levels such that any issues are mitigated, e.g. by using energy (battery or pumped hydro) storage [1-5].

For islanded systems, the risk represents load shedding and unnerved load in the event of a rapid drop of renewable energy output for which the rest of the system cannot compensate. For large interconnected systems it may represent emergency rate penalties for offending utilities. Uzbekistan is the latter case, with an agreed $300 \mathrm{MW}$ float on the interconnector used for regulation for up to 20 minutes [6-11].

The time scale that matters most for our purposes of this study is the 10-minute interval. Over this period, intermittency needs to be able to be covered from already generating units (or stand-by batteries, or pumped storage in synchronous condenser mode). Beyond that period, fast starting units will be able to have come online in response to any events.

In the very short term, fluctuation in renewable energy output are related to cloud coverage and localized gusts, which cancel each other out on larger dispersed numbers of plants. Over longer time frames, the weather patterns will lead to higher correlation (e.g. the wind dying off after a stormy period which will affect the whole plant or the sun setting) [12-13].

In summary, unpredictable short-term intermittency events exhibit lower correlation especially over larger and geographically dispersed plants and therefore cancel each other out. Weather (and sun-cycle) related intermittency occurs over longer time frames and is predictable and can be planned for.

\section{Methods}

In the case of PV, there have been documented cases of small plants suffering an $80 \%$ variation over one (1) minute intervals in the most extreme cases. Five (5) plants separated to the extent they are uncorrelated will have only a $40 \%$ variation and twenty-three (23) PV plants would have only a $20 \%$ variation of available power. Note that this reduced variation is a percentage of the aggregate installed capacity and is therefore larger than $80 \%$ of a single plant. On the basis that the plants are mutually [ 14-16], the expected variation is given in the equation below:

$$
\mathrm{r} \infty \frac{1}{\sqrt{N}}
$$

Where $r$ is the deviation the maximum aggregate available power in per unit, and $\mathrm{N}$ is the number of uncorrelated plants. Fig. 1 presents the above formula graphically for up to 21 plants where the 1-minutes variation for an individual plant is considered to $80 \%$ in this case.

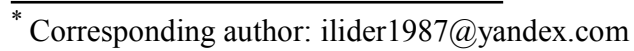




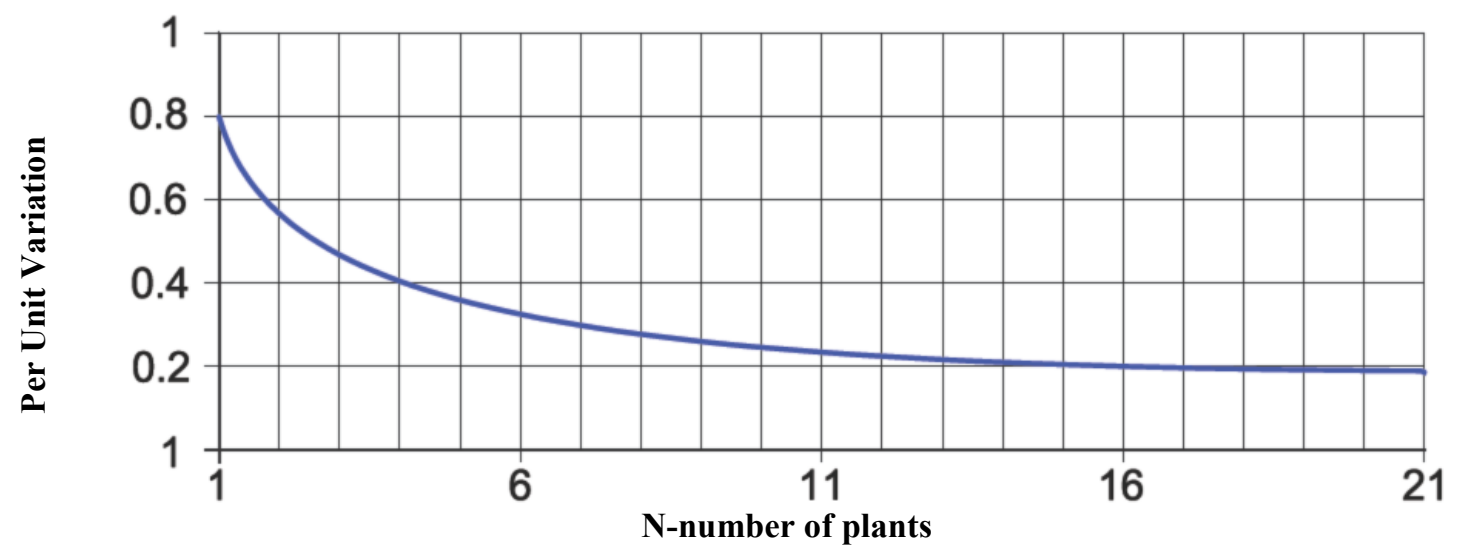

Fig. 1. Per Unit $(\mathrm{N})$ variation of power output on 1-minute intervals for different number of plants

It follows for a given capacity goal, it is beneficial to have a number of smaller plants than fewer larger plants. The above analysis assumes the plants are equal or similar in size and have the same statistical variation and provides a good first approximation where output data is unavailable.

If the plant sizes are known, and output data exists, an approach which considers this information can be used. The equation below provides the solution when considering the plant size as well as the correlation or covariance between any two plants:

$$
\sigma_{\Delta P}^{t}=\sqrt{\operatorname{Var}\left(\Delta P^{t}\right)}=\sqrt{\sum_{i=1}^{n} \sum_{j=1}^{n} \operatorname{Cov}\left(\Delta P_{i}^{t}, \Delta P_{j}^{t}\right)}
$$

The covariance between two plants can be calculated by multiplying their maximum individual variation $\left(\Delta P^{t}\right)$ (where $t$ is the timescale under consideration) with one another and then multiplying by the correlation between the two plants in question. The square root of the summated covariance provides the maximum variation for the time periods while the maximum individual variation can be evaluated using statistical probabilities [17-19].

The data assessed 20 years' worth of hourly wind speed data for three sites and typical meteorological year (TMY) solar irradiance data for five sites in Uzbekistan. In addition, date analyzed two 20 years' worth of 30minute of solar irradiance for two sites in Uzbekistan (highest granularity available). The data run through our statistical models to quantify the correlation of output changes between plants and sites to estimate the overall portfolio risk in terms of the largest acceptable variation that the utility should safeguard against (e.g. 99.7th percentile).

The data points obtained from that can be benchmarked against data in order to extrapolate to the relevant time horizons in order to extrapolate to the relevant time horizons.

In order to assess the expected portfolio standard deviation (as measure of intermittency), we employ portfolio theory

$\sigma_{p}=\sqrt{w_{A}^{2} \sigma_{A}^{2}+w_{B}^{2} \sigma_{B}^{2}+w_{C}^{2} \sigma_{C}^{2}+2 w_{A} w_{B} \rho_{A, B} \sigma_{A} \sigma_{B}+2 w_{B} w_{C} \rho_{B, C} \sigma_{B} \sigma_{C}+2 w_{A} w_{C} \rho_{A, C} \sigma_{A} \sigma_{C}}$ Where

$w_{A}$ is the weight of asset $\mathrm{A}$ in the total portfolio $\left(\mathrm{MW}_{\mathrm{A}}\right.$ / MW portfolio)

$\sigma_{A}^{2}$ is the variance of output of asset A $\mathrm{B}$

$\rho_{A, B}$ is the correlation between output of assets A and

$\sigma_{A}$ is the standard deviation of output asset $\mathrm{A}$ and similarly, for asset $\mathrm{B}$ and asset $\mathrm{C}$, etc. Note that when correlation is 0 , the covariance terms become 0 and can be neglected.

\section{Results and Discussion}

The general results are presented here, in Table 1.

Table 1. High-level results of the correlation analysis of 60-minute Uzbekistan

\begin{tabular}{|c|c|}
\hline Wind correlation & $\begin{array}{c}\text { Correlation between wind sites is slightly positive with coefficients between } \\
19 \% \text { and } 38 \%\end{array}$ \\
\hline Solar correlation & $\begin{array}{c}\text { Correlation between solar sites is highly positive with coefficients between } \\
50 \% \text { and } 79 \%\end{array}$ \\
\hline Cross correlation & wind and solar sites are not correlated close to 0. \\
\hline
\end{tabular}


Table 2. Most extreme and p99,7 output changes over 20 -year date series

\begin{tabular}{|c|c|}
\hline \multicolumn{2}{|c|}{ Per unit (p.u) of installed capacity } \\
\hline Maximum increase (p.u) & 0.311 \\
\hline Maximum Decrease (p.u) & $-0,266$ \\
\hline Mean & 0,000 \\
\hline Variance ( $\sigma 2)$ & 0,026 \\
\hline Std. Dev $(\sigma)$ & 0,057 \\
\hline $99,70 \%$ (increase) & 0,211 \\
\hline $0,30 \%$ (decrease) & $-0,193$ \\
\hline
\end{tabular}

Table 2 presents the results of the analysis of the output variability with the most extreme and the 99,7th percentile variation over the 1-hour time horizon for portfolio plants consisting of 5 solar sites and 3 wind sites (all equal size).

Using a typical logarithmic relationship (as observed elsewhere) and based on the benchmarking of the 60minute and 30-minute variation with the data analyzed for Uzbekistan as well as assessment of correlation coefficients, we can extrapolate to shorter time periods relevant to define the spinning reserves (Figure 2).

The relationship shows that a substantial, albeit less overall, portion of the variation for a plant over an hour, is also required over the 10-minute time frame. Although the overall variability is less, the ramp rate requirements on a 10 minutes basis are much higher than on the 60 minute basis.

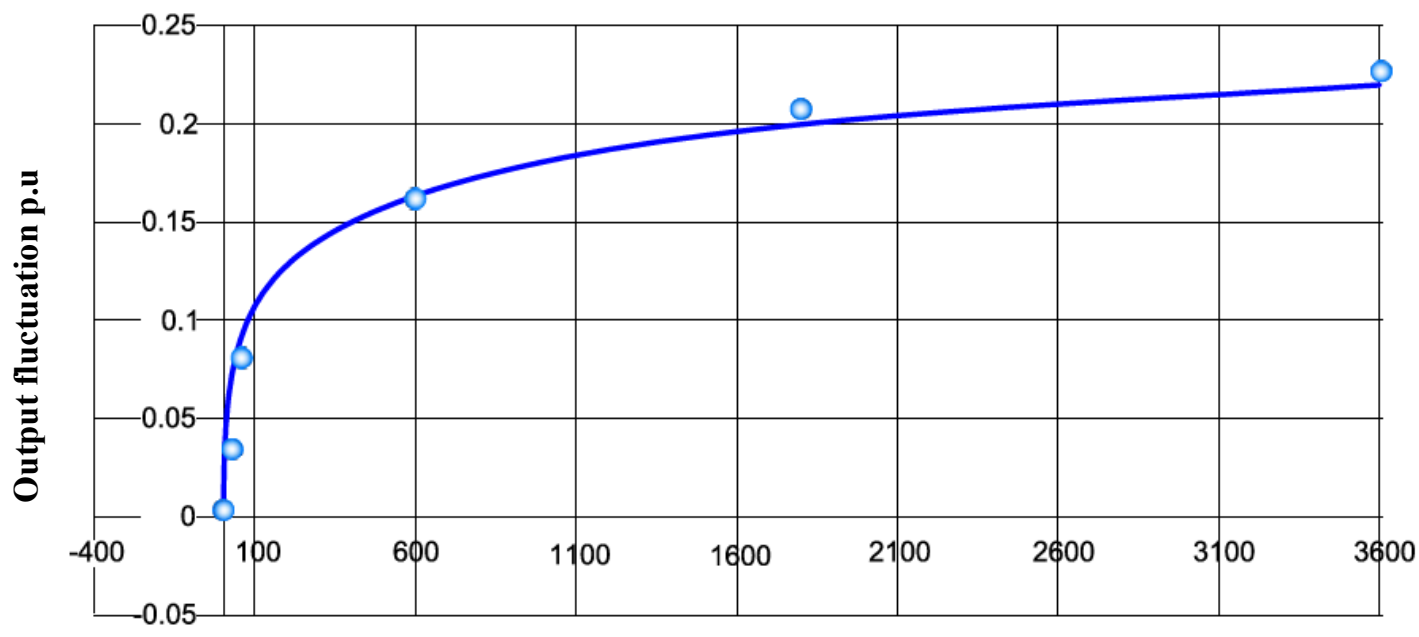

Time in seconds

Fig. 2. Example of per unit output variation over different time for a renewable plant

Table 3. 10 -minute portfolio variation of the sample portfolio

\begin{tabular}{|c|c|c|c|c|}
\hline Comment & $\begin{array}{c}\text { Solar +wind } \\
\text { (per date) }\end{array}$ & $\begin{array}{c}\text { Solar } \\
\text { (only) }\end{array}$ & $\begin{array}{c}\text { Wind } \\
\text { (only) }\end{array}$ \\
\hline $\begin{array}{c}\text { 99,7 percentile } \\
\text { variation (p.u) at 1- } \\
\text { hour interval }\end{array}$ & $\begin{array}{c}\text { Standard variation of change in } \\
\text { output of a single plant }\end{array}$ & 0.40 & 0.28 \\
\hline $\begin{array}{c}\text { 99,7 percentile } \\
\text { variation (p.u) at 10 - } \\
\text { min interval }\end{array}$ & $\begin{array}{c}\text { Assumed as 90\% of the above } \\
\text { given the logarithmic relationship } \\
\text { as per Figure 2 }\end{array}$ & 0.36 & 0.252 \\
\hline Number of sites & Assuming equal size at each site & & 5 & 3 \\
\hline $\begin{array}{c}\text { Standard deviation of } \\
\text { a portfolio }\end{array}$ & $\begin{array}{c}\text { Assuming the different sites are } \\
\text { uncorrelated at the 10-minutes } \\
\text { interval }\end{array}$ & $\begin{array}{c}0.11=\text { sqrt } \\
\left(0.16^{\wedge} 2+0.14 \wedge 2\right)\end{array}$ & $\begin{array}{c}0.16=0.36 / \text { sqrt } \\
5\end{array}$ & $\begin{array}{c}0.14=0.252 / \\
\text { sqrt3 }\end{array}$ \\
\hline
\end{tabular}

Table 4. Spinning Reserve Requirement diversified solar + Wind portfolio of $10 \mathrm{GW}$

\begin{tabular}{|c|c|c|c|}
\hline & Renewable Energy Capacity (MW) & Spinning Reserve (MW) & Ramping (MW) \\
\hline 10 minutes & 10,000 & 1,270 & 127,0 \\
\hline 60 minutes & 10,000 & 2,210 & 36,8 \\
\hline
\end{tabular}


Based on this relationship, we can estimate the portfolio intermittency the utility should keep spinning reserves for as shown in Table 3 [20-24].

In order to remain conservative in our approach for Uzbekistan (given the limited data about sites, composition and sizes of portfolio plants, and lack of highly granular measured data), we estimate the portfolio variation on the hourly interval (which exhibits larger variability than the 10-min interval data would have). We obtain a value of 0,127 per unit (p.u.). This means for a wind and solar plant portfolio of $10 \mathrm{GW}$ in Uzbekistan, even though we estimate that over 1 hour, $2.21 \mathrm{GW}$ of ramp up generation needs to be available $(36.8 \mathrm{MW} / \mathrm{min})$ from Table 2, the short-term ramping requirement is conservatively estimated at $1.27 \mathrm{GW}$ over 10 minutes (127 MW/min) as shown in Table 4 [25-28].

\section{References}

1. Chile's First Solar-Powered Industrial Plant Opens in the Atacama. This Is Chile. Available online: https://www.thisischile.cl/chiles-first-solar-poweredindustrial-plant-opens-in-the-atacama/?lang=en.

2. REN21 2017. Renewables Global Status Report. Renewable Energy Policy Network for the 21st Century, (2016)

3. http://www.apie.com.ar/Boletines/boletin-27/ofertahidro.html

4. Zicmane and K. Berzina, "A Mathematical Model of Optimal Modes of Operation of an Autonomous Energy Complex for a Typical Graph of Changes in the Energy Loads of a Consumer," 2018 International Conference and Exposition on Electrical And Power Engineering (EPE), Iasi, 2018, pp. 279-283. doi: 10.1109/ICEPE.2018.8559666.

5. B. Papkov, A. Mahnitko, I. Zicmane, K. Berzina, T. Lomane and Y. Veremiichuk, "System Approach to Management of Electrical Consumption in Intelligent Electrical Networks," 2019 IEEE International Conference on Environment and Electrical Engineering and 2019 IEEE Industrial and Commercial Power Systems Europe (EEEIC / I\&CPS Europe), Genova, Italy, 2019, pp. 1-6. doi: 10.1109/EEEIC.2019.8783911.

6. Mokhinabonu Mardonova and Yosoon Choi. Assessment of Photovoltaic Potential of Mining Sites in Uzbekistan. Sustainability 2019, 11(10), 2988; https://doi.org/10.3390/su11102988

7. I.U.Rakhmonov, K.M. Reymov, A.M. Najimova, B. Uzakov and B.T. Seytmuratov. Analysis and calculation of optimum parameters of electric arc furnace. APITECH2019. IOP Publishing. Journal of Physics: Conference Series 1399 (2019) 055048. doi:10.1088/1742$6596 / 1399 / 5 / 055048$

8. Uzbekistan Transmission and Distribution Losses Percent. Available online: https://tradingeconomics.com/uzbekistan/transmissio n-and-distribution-losses-percent-wb-data.html (accessed on 12 April 2019).

\section{Conclusion}

Typically, spinning reserve requirements need to be able to regulate the power demand and supply balance in the short term. Primary reserve is often $3-5 \%$ of load available within seconds sustained for a short period. Secondary reserve responds within 10 seconds by ramping up output and sustains the output response for 30 minutes, at which point fast reserve units will have started. In the future, it would be expected that more data for Uzbekistan is collected and generated, especially when solar and wind plants become operational, so that this analysis can be refined further on an ongoing basis. The higher the resolution of this data (e.g. power output on a 1- or 10-minute basis), the more accurate the updated analysis will be

9. UZBEKENERGO: Tariffs Electric Power. Available online:

https://www.uzbekenergo.uz/uz/activities/tariffselectric-power/ (accessed on 23 April 2019). 10. Global Solar Atlas-Downloads. Available online: https://globalsolaratlas.info/downloads/uzbekistan (accessed on 25 April 2019)

11. Bank, A.D. Solar Energy Development Roadmap; ASIAN DEVELOPMENT BANK UZB TA 8008 Republic of Uzbekistan: Manila, Philippines, 2014.

12. State Committee of the Republic of Uzbekistan: Alternative Energy Sources of Uzbekistan. Available online: $\quad$ https://www.stat.uz/ru/ofitsialnayastatistika/investitsii-i-stroitelstvo/statisticheskietablitsy/439-byulleteni-ru/2819-ispolzovaniealternativnykh-istochnikov-energii-v-uzbekistane (accessed on 25 April 2019).

13. Saidkhodjaev A G, Najimova A M and Bijanov A K 2019 Method for determining the maximum load of consumers in city power supply systems E3S Web Conf 139 doi:10.1051/e3sconf/201913901078.

14. Taslimov A D, Rakhmonov I U 2019 Optimization of complex parameters of urban distribution electric networks Journal of Physics: Conference Series 1399 doi:10.1088/1742-6596/1399/5/055046

15. Taslimov A D, Berdishev A S, Melikuzuev M V and Rakhimov F M 2019 Method of selecting parameters of cable lines distributive networks $10 \mathrm{kv}$ in uncertainty conditions $\quad E 3 S \quad W e b \quad 139$ doi:10.1051/e3sconf/201913901082

16. Taslimov A D, Berdishev A S, Melikuziyev M V and Rakhimov F M 2019 Method of choosing the unification of cable sections of electric network cables under conditions of load development uncertainty E3S Web Conf 139 doi:10.1051/e3sconf/201913901081 17. Rakhmonov, I.U., Nematov, L.A., Niyozov, N.N, Reymov, K.M., Yuldoshev, T.M. (2020) Power consumption management from the positions of the general system theory Journal of Physics: Conference Series 1515 doi:10.1088/1742-6596/1515/2/022054

18. E.G.Usmanov, A.N.Rasulov, M.K.Bobojanov, R.Ch.Karimov. E3S Web of Conferences 139, 01079 (2019), doi.org/10.1051/e3sconf/201913901079 
19. Bobojanov M.K., Rasulov A.N., Karimov R.Ch., Sattarov H.A. Bulletin Descendants of Mohammed AlKhwarizmi (ISSN: 2181-9211), Tashkent, 3(5), - PP.106109, (2018).

20. Burievich, T.J. The questions of the dynamics of drilling bit on the surface of well bottom// Arch. Min. Sci. -Poland. - Vol. 61 (2016). - №2. - P. 279-287. DOI 10.1515/amsc-2016-0020.

21. Toshniyozov, L.G., Toshov, J.B. Theoretical and experimental research into process of packing in drilling// Mining Informational and Analytical Bulletin Volume 2019, Issue 11, 2019, Pages 139-151. DOI: 10.25018/0236-1493-2019-11-0-139-151.

22. Mannanov U., Toshov J., Toshniyozov L. Perspective Solutions for the Design of Drilling Tools / E3S Web of Conferences 105, 03027 (2019) IVth International Innovative Mining Symposium, https://doi.org/10.1051/e3sconf/201910503027

23. Azamatovich, A.N., Amrillo, M.B, Burievich, T.J., Umarxanoxich, J.R., Shavkatovich, Z.A. A complex of methods for analyzing the working fluid of a hydrostatic power plant for hydraulic mining machines / International Journal of Advanced Science and Technology. Volume 29, Issue 5 Special Issue, 28 March 2020, Pages 852-855 24. Hoshimov, F.A., Bakhadirov, I.I., Erejepov, M., Djumamuratov, B. (2019) Development of method for normalizing electricity consumption E3S Web Conf 139 doi:10.1051/e3sconf/201913901074

25. Allayev, K.R., Fedorenko, G.M.,Postnikov, V.I.,Ostapchuk, L.B. Asynchronous generators as power system's natural dampers. 43rd International Conference on Large High Voltage Electric Systems 2010, CIGRE 20102010, 9p43rd International Conference on Large High Voltage Electric Systems 2010, CIGRE 2010; Paris; France; 22 August 2010.

26.Fazylov, Kh.F.,Allaev, K.R. Analysis of the operation of an electrical system during simultaneous operation of synchronous and asynchronous generators. Power engineering New York Volume 18, Issue 3, 1980, Pages 81-88.

27.Fazylov, Kh.F.,Allaev, K.R. Asynchronous turbogenerators with stator excitation and the prospects for their utilization. Power engineering New York Volume 23, Issue 2, 1985, Pages 7-13.

28.Fazylov, Kh.F.,Allaev, K.R. Calculation and experimental analysis of conditions of electrical power systems containing induction generators Power Engineering New York Volume 27, Issue 6, 1989, Pages 27-34. 